\title{
Willingness to Receive COVID-19 Vaccination Among People Living With HIV and AIDS in China: Nationwide Cross-sectional Online Survey
}

Xiaojie Huang ${ }^{1 *}, \mathrm{PhD}$; Maohe $\mathrm{Yu}^{2 *}, \mathrm{PhD}$; Gengfeng $\mathrm{Fu}^{3 *}, \mathrm{PhD}$; Guanghua Lan ${ }^{4 *}, \mathrm{PhD}$; Linghua $\mathrm{Li}^{5^{*}}, \mathrm{PhD}$; Jianzhou Yang $^{6^{*}}$, MPH; Ying Qiao ${ }^{7 *}$, MPH; Jin Zhao ${ }^{8^{*}}$, PhD; Han-Zhu Qian ${ }^{9}$, PhD; Xiangjun Zhang ${ }^{10}$, PhD; Xinchao Liu ${ }^{11}$, PhD; Xia Jin ${ }^{12}$, MPH; Guohong Chen ${ }^{3}$, MPH; Hui Jiang ${ }^{13}$, PhD; Weiming Tang ${ }^{14^{*}}$, PhD; Zixin Wang ${ }^{13^{*}}$, PhD; Junjie $\mathrm{Xu}^{15^{*}}, \mathrm{PhD}$

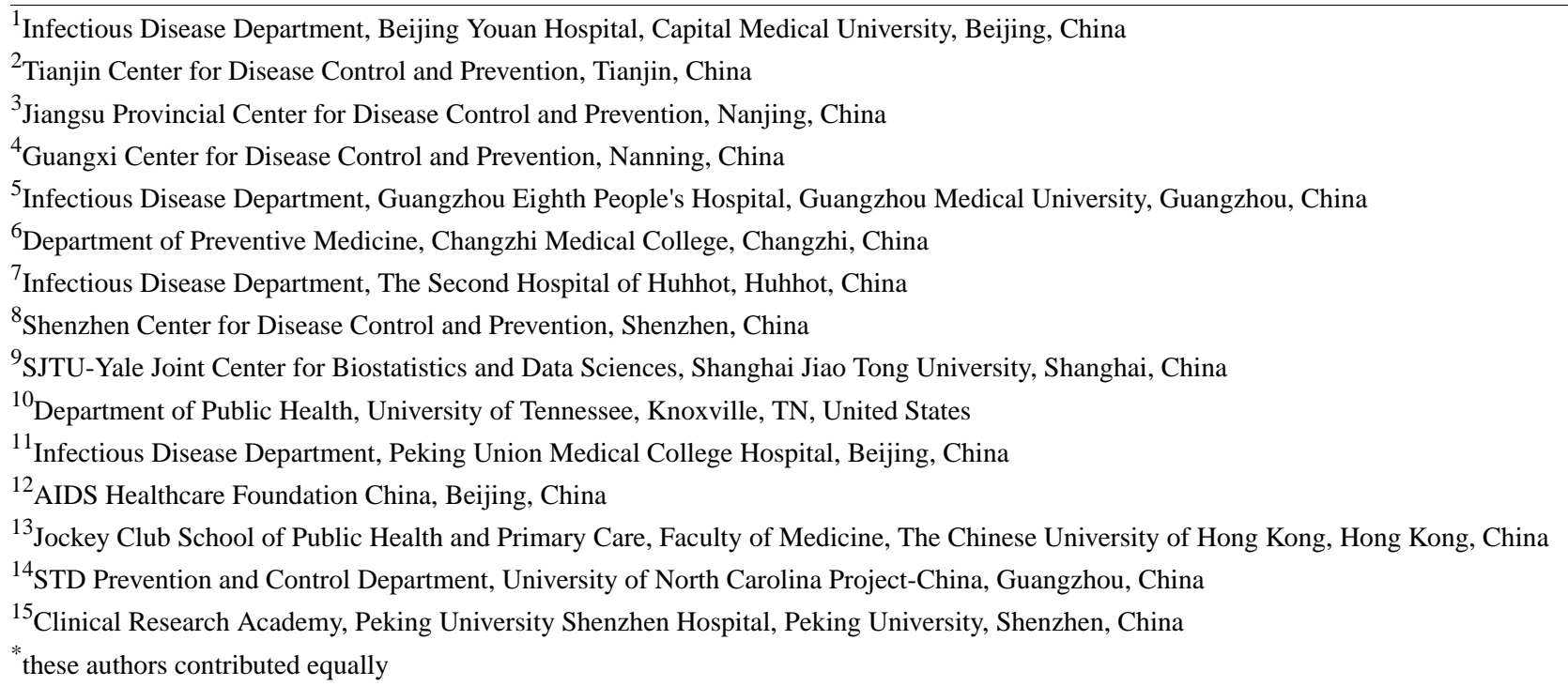

\section{Corresponding Author:}

Zixin Wang, PhD

Jockey Club School of Public Health and Primary Care

Faculty of Medicine

The Chinese University of Hong Kong

Room 508, School of Public Health, Prince of Wales Hospital, Shatin, NT

Hong Kong, 666888

China

Phone: 85222528740

Fax: 85226453098

Email: wangzx@cuhk.edu.hk

\section{Abstract}

Background: HIV infection is a significant independent risk factor for both severe COVID-19 presentation at hospital admission and in-hospital mortality. Available information has suggested that people living with HIV and AIDS (PLWHA) could benefit from COVID-19 vaccination. However, there is a dearth of evidence on willingness to receive COVID-19 vaccination among PLWHA.

Objective: The aim of this study was to investigate willingness to receive COVID-19 vaccination among a national sample of PLWHA in China.

Methods: This cross-sectional online survey investigated factors associated with willingness to receive COVID-19 vaccination among PLWHA aged 18 to 65 years living in eight conveniently selected Chinese metropolitan cities between January and February 2021. Eight community-based organizations (CBOs) providing services to PLWHA facilitated the recruitment. Eligible 
PLWHA completed an online survey developed using a widely used encrypted web-based survey platform in China. We fitted a single logistic regression model to obtain adjusted odds ratios (aORs), which involved one of the independent variables of interest and all significant background variables. Path analysis was also used in the data analysis.

Results: Out of 10,845 PLWHA approached by the CBOs, 2740 completed the survey, and 170 had received at least one dose of the COVID-19 vaccine. This analysis was performed among 2570 participants who had never received COVID-19 vaccination. Over half of the participants reported willingness to receive COVID-19 vaccination (1470/2570, 57.2\%). Perceptions related to COVID-19 vaccination were significantly associated with willingness to receive COVID-19 vaccination, including positive attitudes (aOR 1.11, 95\% CI 1.09-1.12; $P<.001$ ), negative attitudes (aOR 0.96, 95\% CI 0.94-0.97; $P<.001$ ), perceived support from significant others (perceived subjective norm; aOR 1.53, 95\% CI 1.46-1.61; $P<.001$ ), and perceived behavioral control (aOR 1.13, 95\% CI 1.11-1.14; $P<.001$ ). At the interpersonal level, receiving advice supportive of COVID-19 vaccination from doctors (aOR 1.99, 95\% CI 1.65-2.40; $P<.001$ ), CBO staff (aOR 1.89, 95\% CI 1.51-2.36; $P<.001$ ), friends and/or family members (aOR 3.22, 95\% CI 1.93-5.35; $P<.001$ ), and PLWHA peers (aOR 2.38, 95\% CI 1.85-3.08; $P<.001$ ) was associated with higher willingness to receive COVID-19 vaccination. The overall opinion supporting COVID-19 vaccination for PLWHA on the internet or social media was also positively associated with willingness to receive COVID-19 vaccination (aOR 1.59, 95\% CI 1.31-1.94; $P<.001)$. Path analysis indicated that interpersonal-level variables were indirectly associated with willingness to receive COVID-19 vaccination through perceptions $(\beta=.43,95 \% \mathrm{CI} .37-.51 ; P<.001)$.

Conclusions: As compared to PLWHA in other countries and the general population in most parts of the world, PLWHA in China reported a relatively low willingness to receive COVID-19 vaccination. The internet and social media as well as interpersonal communications may be major sources of influence on PLWHA's perceptions and willingness to receive COVID-19 vaccination.

(JMIR Public Health Surveill 2021;7(10):e31125) doi: 10.2196/31125

\section{KEYWORDS}

people living with HIV and AIDS; COVID-19 vaccination; willingness; perceptions; internet and social media influences; interpersonal communication

\section{Introduction}

The World Health Organization (WHO) confirmed that HIV infection is a significant independent risk factor for both severe COVID-19 presentation at hospital admission and in-hospital mortality [1]. It is essential to take additional measures to prevent people living with HIV and AIDS (PLWHA) from contracting COVID-19.

The COVID-19 vaccine offers the best hope for ending the pandemic. Simulation experiments showed that when vaccine efficacy was $80 \%, 75 \%$ coverage could end the COVID-19 pandemic without any other control measures [2]. A relatively small number of PLWHA were involved in phase III COVID-19 vaccine trials. The Pfizer study and the Oxford/AstraZeneca study recruited 196 and 157 PLWHA, respectively; however, the data on vaccine efficacy for PLWHA was not included in the publications that led to their approval in the United States and the United Kingdom [3,4]. The Moderna study included 176 PLWHA [5]. Of the PLWHA in the Moderna study, one person who received the placebo and none who received the vaccine developed COVID-19. The Janssen (Johnson \& Johnson) study included 1218 PLWHA [6]. Two PLWHA who received the vaccine and four who received the placebo developed COVID-19. There were 201 PLWHA in the Novavax study; the overall vaccine efficacy was $49.4 \%$, with a higher efficacy when PLWHA were excluded from the analysis (60\%) [7]. A number of studies observed similar immune responses and adverse events in response to messenger RNA (mRNA) and adenovirus vector COVID-19 vaccines between PLWHA and HIV-negative individuals [8-12]. Despite limited evidence, available information suggests that COVID-19 vaccines recommended by the WHO are safe for PLWHA.
There is no evidence to support a less robust response to COVID-19 vaccines among PLWHA. PLWHA could benefit from COVID-19 vaccination.

The recommendations or guidelines regarding COVID-19 vaccination for PLWHA are inconsistent across countries. The WHO, the United States Department of Health and Human Services, the British HIV Association, and health authorities in Australia recommend that PLWHA receive COVID-19 vaccination regardless of their CD4+ $\mathrm{T}$ cell counts [1,13-15]. PLWHA comprise one of the priority groups to receive COVID-19 vaccination in the United Kingdom, the United States, and Australia [13-15]. Moreover, the United States Centers for Disease Control and Prevention recommends that PLWHA who are moderately to severely immunocompromised should receive an additional dose of mRNA COVID-19 vaccine after the initial doses [16]. In the Asia-Pacific region, Singapore used to recommend COVID-19 vaccination to PLWHA who are receiving antiretroviral therapy (ART), with suppressed HIV viral load, and with CD4+ T cell counts over 200 cells/ $\mu \mathrm{L}$ [17]. Their recommendation expanded to all PLWHA regardless of ART, viral suppression, or CD4+ T cell counts since July 2021 [17]. At the time when this study was conducted, immunodeficiency, including HIV infection, was listed as a precaution for COVID-19 vaccination in China; PLWHA were asked to seek advice from doctors regarding COVID-19 vaccination [18]. The guideline was updated one month after the completion of this study (March 2021) and recommended COVID-19 vaccination for PLWHA, regardless of their CD4+ T cell counts [18].

Vaccine hesitancy hindered the successful control of the COVID-19 pandemic. Therefore, it is helpful for governments to plan interventions to improve people's awareness of the safety 
and benefits of the COVID-19 vaccine and to reduce vaccine hesitancy. In order to promote the COVID-19 vaccination of PLWHA, it is necessary to understand their willingness to receive COVID-19 vaccination and related facilitators and barriers. However, most studies investigating willingness to receive COVID-19 vaccination and its associated factors were conducted among the general population and medical professionals [19-21]; therefore, the findings might not be applicable to PLWHA. To our knowledge, only two published studies investigated COVID-19 vaccine hesitancy among PLWHA in the United States and France [22,23]. The results showed that $28.7 \%$ of PLWHA in France declared hesitancy to be vaccinated against COVID-19 [22]. Over 30\% of PLWHA in the United States indicated that if a vaccine was available to prevent COVID-19, they would not trust it (34\%) nor want to get it $(32 \%)$ [23]. Concerns about their health and the belief that COVID-19 vaccination should be mandatory and is important for people with chronic disease were associated with higher willingness to receive COVID-19 vaccination among PLWHA, while a previous history of vaccination refusal, mistrust in public health information, and concerns related to side effects were shown to be barriers [22,23].

We applied the socioecological model to understand factors associated with willingness to receive COVID-19 vaccination among PLWHA at individual, interpersonal, and sociostructural levels [24]. Interventions addressing influencing factors at multiple levels are more likely to be successful [24]. The socioecological model was used successfully to explain compliance to COVID-19 personal preventive measures among Chinese populations [25]. At the sociostructural level, two COVID-19 vaccination delivery models were implemented simultaneously in China at the time of this study. Individuals could make an appointment to receive COVID-19 vaccination in some cities, while COVID-19 vaccination was mainly arranged by employers and did not allow individuals to make appointments in other Chinese cities. People had the right to refuse such an arrangement. As of the writing of this paper, since the number of vaccines is inadequate to cover the entire Chinese population at the initial phase, priority is given to subgroups with elevated risks of developing COVID-19 (eg, health care workers, pandemic-control staff, and cold-chain workers). Some Chinese cities also reported a shortage of COVID-19 vaccines. We expected that these sociostructural-level factors would influence PLWHA's willingness to receive COVID-19 vaccination. At the individual level, perceived efficacy, concerns about side effects, others' acceptance, and confidence to receive the vaccine influenced people's willingness to receive COVID-19 vaccination [26-30]. At the interpersonal level, people were exposed to information related to COVID-19 vaccination through interpersonal communication or the internet and social media. Higher exposure to positive information related to COVID-19 vaccination on social media was associated with a higher willingness to receive such vaccination among Chinese factory workers [27]. Interpersonal communication, such as receiving advice from doctors and family members, was also positively associated with willingness to receive COVID-19 vaccination among the general population in China [28]. Clinical doctors and staff from community-based organizations (CBOs) are the main service providers for PLWHA [31]. Their advice regarding COVID-19 vaccination may have a great impact on PLWHA's decisions to accept such vaccination. A recent study suggested that exposure to positive information related to COVID-19 vaccination increased perceptions favoring such vaccination [27]. In this study, we hypothesized that exposure to information supporting PLWHA in receiving COVID-19 vaccination through the internet and social media as well as interpersonal communication would influence PLWHA's perceptions of such vaccination and, hence, affect their willingness to receive COVID-19 vaccination.

To our knowledge, no studies have investigated willingness to receive COVID-19 vaccination among PLWHA in China. To address knowledge gaps, this study investigated willingness to receive COVID-19 vaccination among a national sample of PLWHA. We examined the effects of the following factors: sociodemographics, HIV-related characteristics, individual-level factors (ie, perceptions related to COVID-19 vaccination), interpersonal-level variables (ie, exposure to COVID-19 vaccination-related information through the internet and social media as well as interpersonal communication), and sociostructural-level factors (ie, COVID-19 vaccination delivery model, members of priority groups, and shortage in vaccine supply). We further tested the hypothesis that perceptions of COVID-19 vaccination would mediate the association between interpersonal-level variables and willingness to receive COVID-19 vaccination.

\section{Methods}

\section{Study Design}

This study makes use of a multicenter cross-sectional online survey conducted in eight conveniently selected large Chinese cities between January and February 2021. These cities included two in the north (Tianjin and Beijing), two in the northeast (Shenyang and Hohhot), one in the east (Nanjing), and three in the south (Nanning, Guangzhou, and Shenzhen). Beijing is the capital city of China. Shenzhen is a major special economic zone in China bordering Hong Kong in the south. The other six cities are capital cities of the provinces. Reasons for selecting these cities included the following: (1) each city has a CBO providing services to PLWHA, (2) each city has a large number of PLWHA, and (3) COVID-19 vaccination was first scaled up at these sites. At the time of this study, people in Beijing, Guangzhou, and Shenzhen could make an appointment to receive COVID-19 vaccination. The procedures of making an appointment were simple. People first downloaded a smartphone app developed by the health bureau. After logging in, they could choose the time and location to receive COVID-19 vaccination. In the other five cities, vaccination was arranged by employers and did not allow individuals to make appointments. Only two types of inactivated COVID-19 vaccines-Sinovac-CoronaVac and Sinopharm-were available in China during the study period. They were provided by designated community vaccination centers and people could only receive them at sites in these centers. Immunodeficiency, including HIV infection, was listed as a precaution for COVID-19 vaccination in China during the study period; it was recommended that PLWHA seek 
advice from doctors regarding COVID-19 vaccination [18]. were asked about their willingness to receive the vaccination. Participants who had never received COVID-19 vaccination The context of this study is shown in Figures 1 to 3 .

Figure 1. Number of patients living with HIV and AIDS in different study sites.

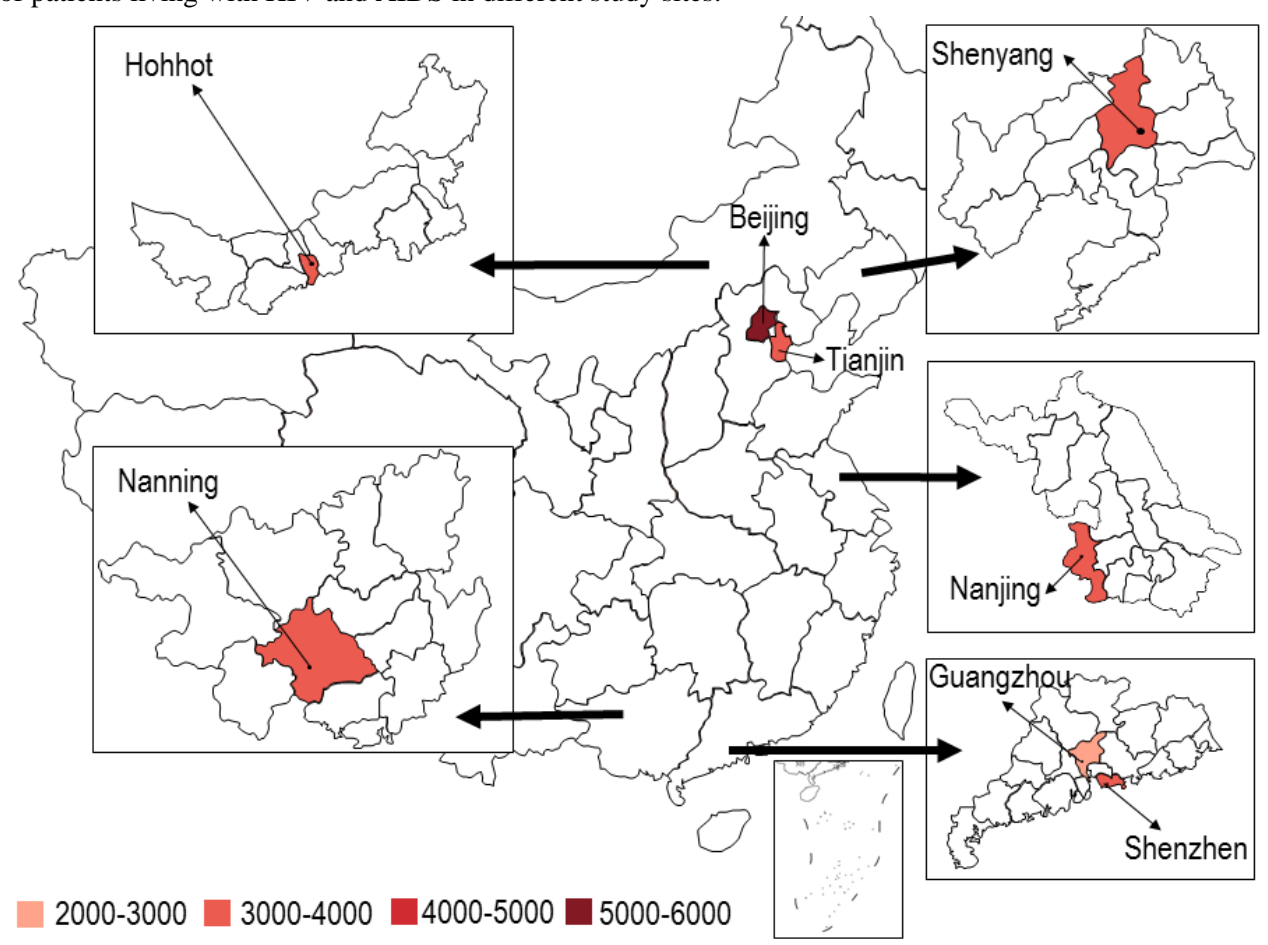

Figure 2. Number of participants in different study sites.

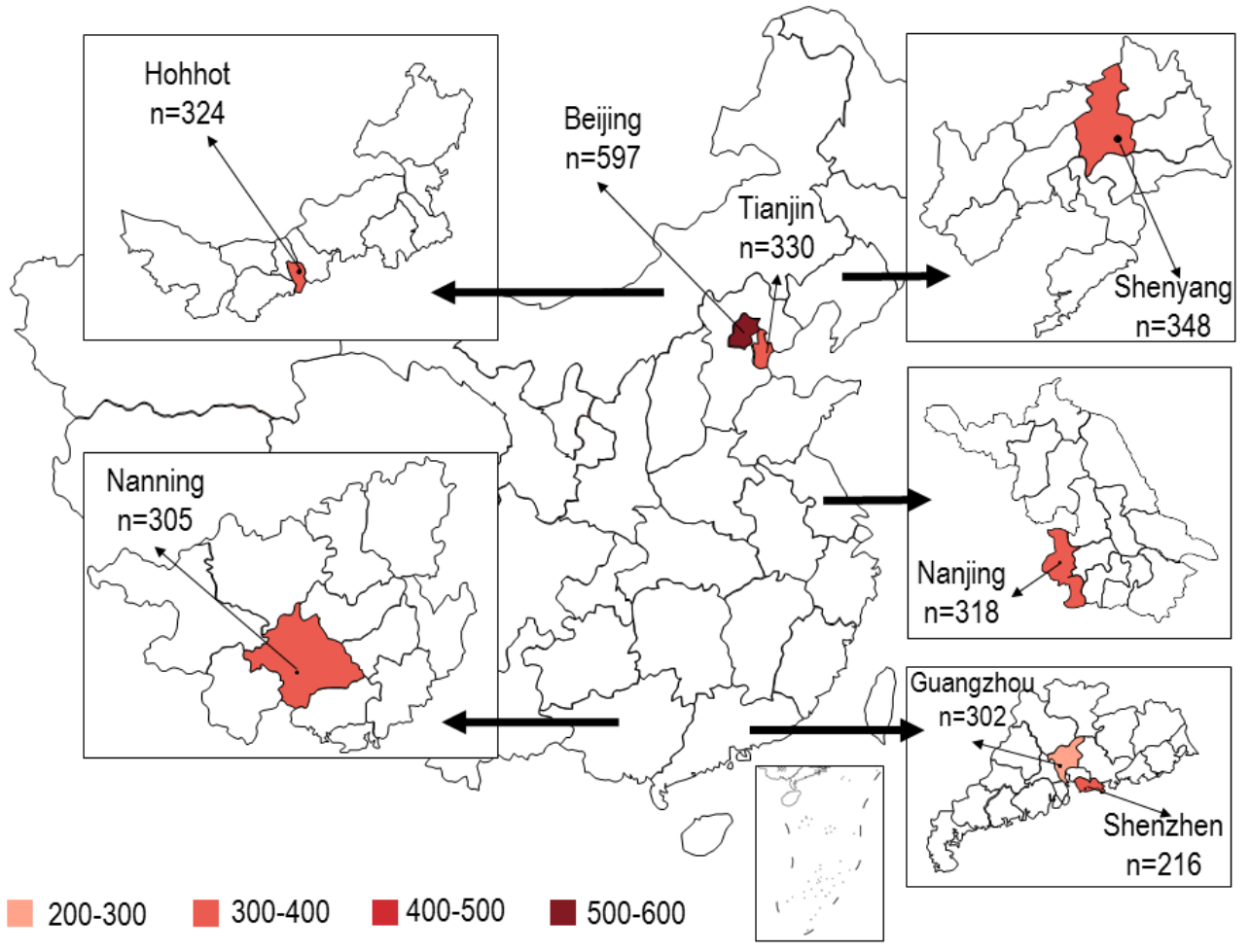


Figure 3. Participants' ability ("Yes") or inability ("No") to make appointments to receive COVID-19 vaccination in different study sites.

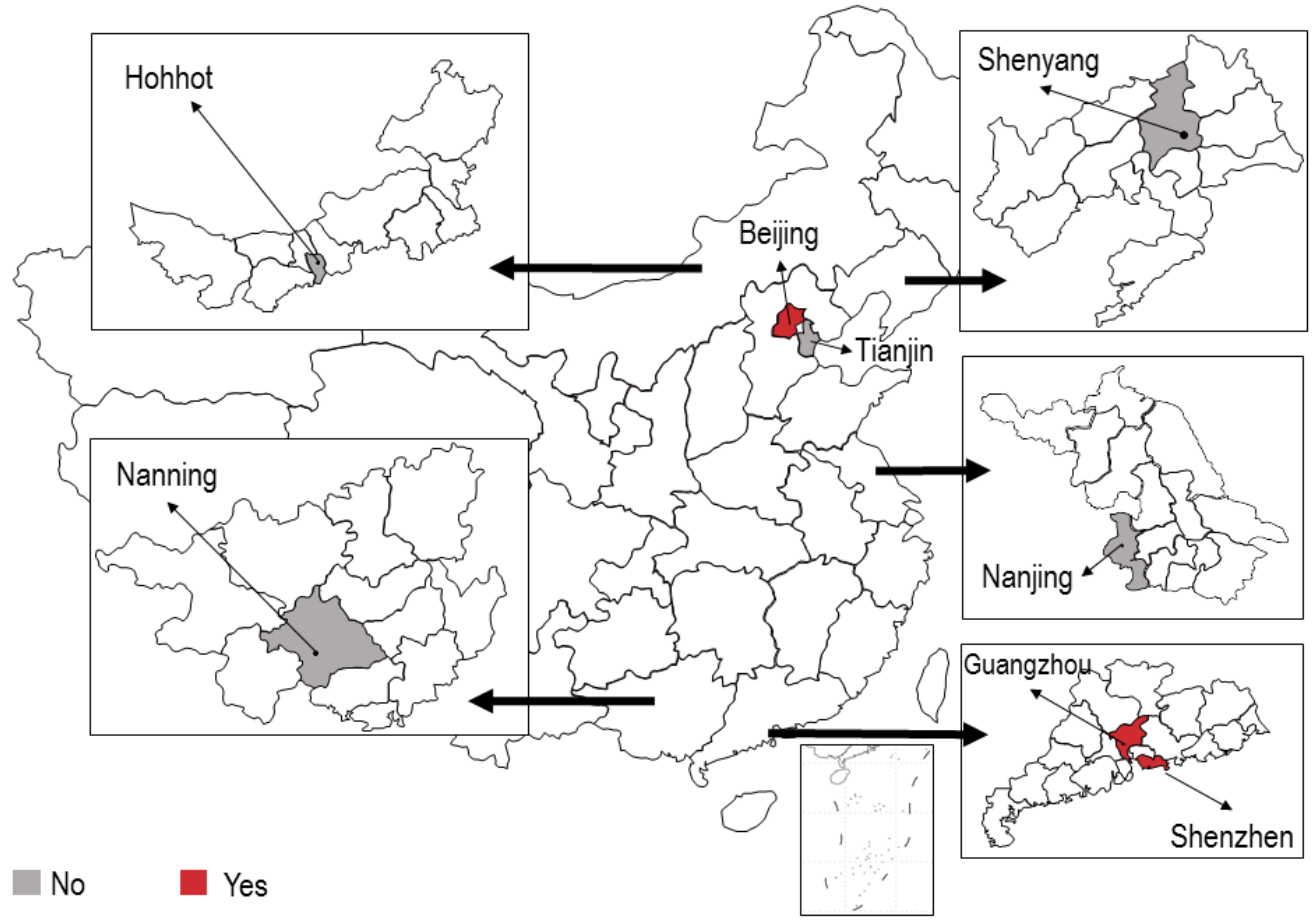

\section{Study Population}

Study participants included individuals aged 18 to 65 years who have been diagnosed with HIV or AIDS and were living in one of the eight cities. We did not include PLWHA older than 65 years, as COVID-19 vaccination was not approved for this age group in China at the time of the survey. Exclusion criteria included the following: (1) being illiterate and unable to complete the questionnaire survey and (2) being ineligible for COVID-19 vaccination (eg, pregnancy, latency, and severe allergy to previous vaccination).

\section{Recruitment and Data Collection}

The eight CBOs that were mainly providing services to marginalized populations (eg, PLWHA and HIV high-risk populations), one in each study site, facilitated recruitment through their networks. These CBOs have been working closely with HIV clinical service providers. CBOs in China are the main providers of HIV outreach services to PLWHA, as these routine tasks have been transferred from government agencies to CBOs [31]. A high proportion of PLWHA are followed up by the CBOs. WeChat is the most common live-chat app used by CBOs to connect with PLWHA clients. The research team provided training for $\mathrm{CBO}$ staff who were responsible for communications with PLWHA within the scope of their routine service. Participants were recruited by posting advertisements in the WeChat groups involving PLWHA clients kept by the CBOs. The advertisements contained study information and contacts of project staff (ie, private WeChat account number and telephone number). Interested participants were asked to contact CBO staff either using private WeChat messages or telephone calls. CBO staff screened prospective participants using the eligibility criteria, introduced the study purpose and procedures, answered questions, and explained the confidentiality of study participation. Participation in this study was voluntary, and participants could refuse to answer any of the questions and withdraw from the study at any time without consequences. Participants signed an electronic consent form sent via WeChat messages. A link to access an online self-administered questionnaire was sent to the consented participants.

The survey was carried out through Golden Data, a commonly used, encrypted, web-based survey platform in China. Each individual WeChat account was allowed to access the online questionnaire only once to avoid duplicate responses. The Golden Data tool performed a completeness check before each questionnaire was submitted. Participants could review and change their responses when they completed the questionnaire. The survey took about 13 to 15 minutes to complete. An electronic coupon with a value of 20 Chinese yuan (US \$3.1) was sent to each participant upon the completion of the survey. A unique ID was assigned to each participant, which was used to delink the study database from personal identifying data. All data collected by the online surveys were stored in the Golden Data server and protected by a password. Only the designated research team members had access to the database.

\section{Ethics Approval and Consent to Participate}

Signed electronic informed consent forms were obtained from all subjects involved in the study. These were kept separately from the empirical data and stored in a password-protected computer or a locked cabinet in the same locked office. This study was conducted according to the guidelines of the Declaration of Helsinki and approved by the Institutional Review Boards of Changzhi Medical College (protocol code RT2021003). 


\section{Measurements}

\section{Development of the Questionnaire}

A panel consisting of public health researchers, health psychologists, clinicians, CBO staff, and PLWHA was formed to develop the questionnaire used in this study. The panel revised and finalized the questionnaire based on a pilot test among 10 PLWHA. These 10 PLWHA did not participate in the actual survey.

\section{Background Characteristics}

Participants reported sociodemographic characteristics, lifestyles (ie, smoking and alcohol drinking), height and weight, and history of other vaccinations in the past 3 years. Participants were also asked whether they had any chronic conditions, such as chronic cardiovascular, respiratory, kidney, and liver diseases; hypertension; diabetes mellitus and its chronic complications; cancers; lymphoma; leukemia; autoimmune diseases; hemorrhagic diseases; and history of severe allergy. The survey also collected some characteristics related to HIV infection (eg, time since HIV diagnosis, whether they were receiving ART, HIV viral load and CD4+ T cell count in the most recent episode of testing, and self-reported severity of AIDS-related symptoms).

\section{Willingness to Receive COVID-19 Vaccination}

Participants were asked about their likelihood of receiving free COVID-19 vaccination in the future; the response categories were as follows: 1 (very unlikely), 2 (unlikely), 3 (neutral), 4 (likely), and 5 (very likely). This study defined willingness to receive COVID-19 vaccination as the responses "likely" or "very likely" [27].

\section{Variables at the Sociostructural, Individual, and Interpersonal Levels Related to COVID-19 Vaccination}

The research team interviewed staff from the Chinese Center for Disease Control and Prevention who were responsible for implementing the COVID-19 vaccination program about whether individuals were allowed to make an appointment to receive COVID-19 vaccination and whether there was a shortage of COVID-19 vaccines during the project period at different study sites. Participants were asked whether they belonged to any of the groups who had priority to receive COVID-19 vaccination as listed by the National Health Commission during the project period.

At the individual level, four scales were constructed to measure perceptions related to COVID-19 vaccination. These scales were as follows: (1) the 5-item Positive Attitude Scale, (2) the 5-item Negative Attitude Scale, (3) the 4-item Perceived Subjective Norm Scale (ie, whether significant others would support them to receive COVID-19 vaccination), and (4) the 5-item Perceived Behavioral Control Scale (ie, how much control PLWHA have for receiving COVID-19 vaccination). Response categories were as follows: 1 (strongly disagree), 2 (disagree), 3 (neutral), 4 (agree), and 5 (strongly agree). Positive and negative attitudes, perceived subjective norm, and perceived behavioral control were significantly associated with willingness to receive COVID-19 vaccination among Chinese people [27].

For interpersonal-level variables, participants were asked whether they received advice given by doctors, CBO staff, friends and/or family members, and other PLWHA regarding COVID-19 vaccination. Participants were also asked about the overall opinion regarding COVID-19 vaccination that they found on the internet or social media; response categories were as follows: 1 (against taking up COVID-19 vaccination), 2 (no advice/neutral), and 3 (supportive in taking up COVID-19 vaccination).

\section{Statistical Analysis}

Using willingness to receive COVID-19 vaccination as the dependent variable and background characteristics as independent variables, crude odds ratios were obtained by logistic regression models. After adjusting for variables with $P<.05$ in the univariate analysis, associations between independent variables of interest (ie, individual-, interpersonal-, and sociostructural-level variables) and the dependent variable were then assessed by adjusted odds ratios (aORs) and 95\% CIs. Each aOR was obtained by fitting a single logistic regression model, which involved one of the independent variables of interest and all significant background characteristics.

Path analysis was conducted to test the mediation model. The mean scores of the Positive Attitude Scale, the Negative Attitude Scale, the Perceived Subjective Norm Scale, and the Perceived Behavioral Control Scale were used as indicators to represent the latent variable of perceptions related to COVID-19 vaccination. The mean scores of advice given by doctors, CBO staff, friends and/or family members, and other PLWHA, as well as the overall opinion on the internet and social media, were used as indicators to represent the latent variable of interpersonal-level variables. Confirmatory factor analysis was conducted to test goodness of fit of these constructs. The latent variable representing perceptions was used as the independent variable, and willingness to receive COVID-19 vaccination was used as the dependent variable. The significant background characteristics were controlled for the model. Goodness of fit was tested using chi-square tests, the comparative fit index (CFI), the Tucker-Lewis index (TLI), and the root mean square error of approximation (RMSEA). Standardized path coefficients $(\beta)$ and unstandardized path coefficients $(B)$ were reported. The asymmetric CIs based on the bootstrap method (10,000 times) that were used for significance testing of mediation hypotheses with the $95 \%$ bootstrap CI did not include zero, indicating a statistically significant mediation effect. The level of statistical significance was set at $P<.05$. SPSS for Windows (version 21.0; IBM Corp) and Mplus (version 8.3; Muthén and Muthén) were used for all analyses.

\section{Results}

\section{Background Characteristics}

The CBOs approached 10,845 PLWHA in their WeChat groups, 8692 accessed the online survey, 2740 completed the survey, and 170 received at least one dose of COVID-19 vaccination at the time of the survey. This study was based on 2570 eligible participants who had never received COVID-19 vaccination; the flowchart of this study is presented in Figure 4. 
Figure 4. Flowchart of data collection. CBO: community-based organization; PLWHA: people living with HIV and AIDS.

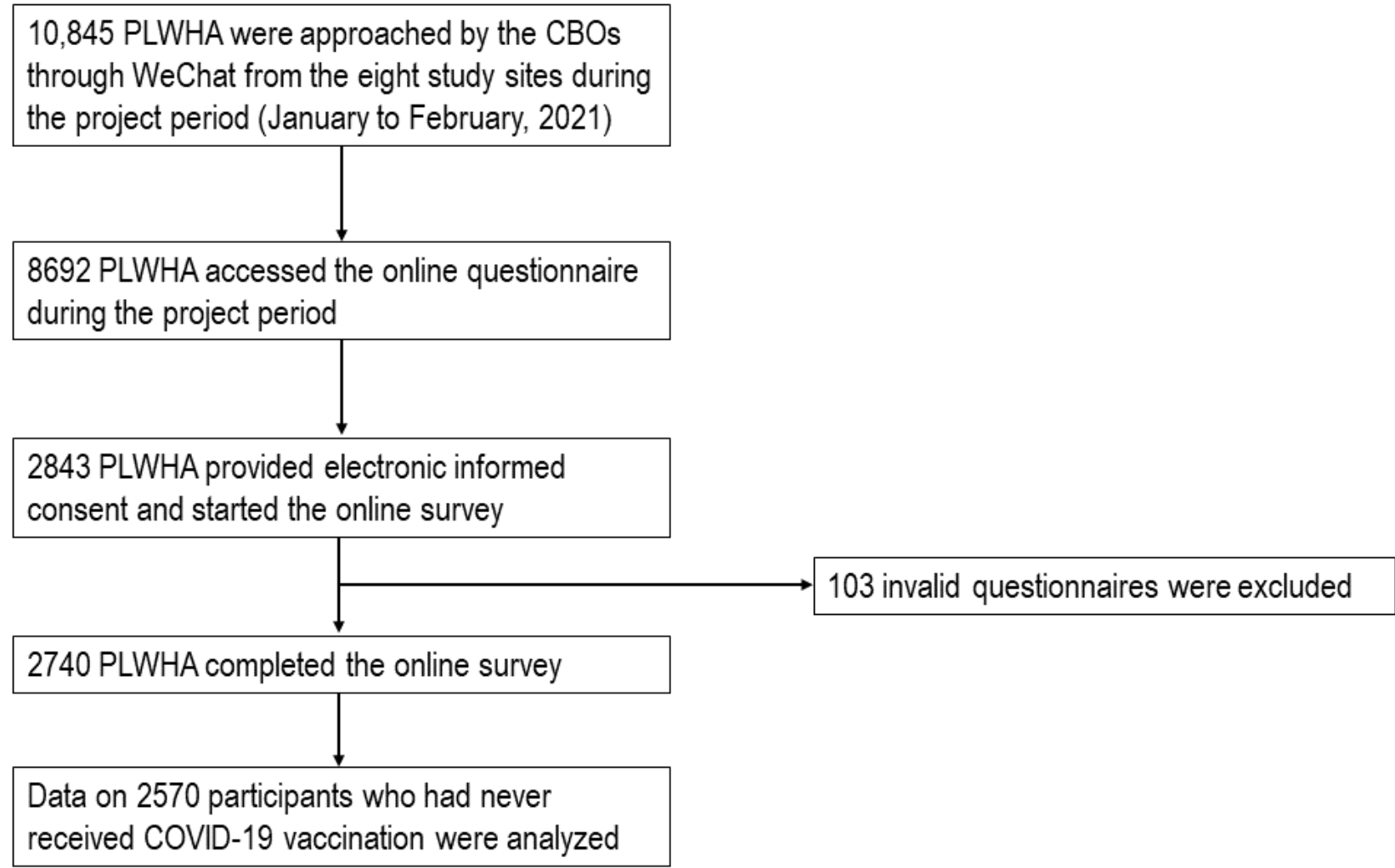

The majority of the 2570 participants were 18 to 39 years of age $(n=1916,74.6 \%)$, identified themselves as male $(n=2106$, $81.9 \%)$, were currently single $(\mathrm{n}=1750,68.1 \%)$, had a full-time job $(\mathrm{n}=1782,69.3 \%)$, and only had basic health insurance $(\mathrm{n}=1927,75.0 \%)$. Regarding characteristics related to HIV infection, $17.2 \%(n=443)$ of the 2570 participants received their diagnosis within 1 year, $97.3 \%(\mathrm{n}=2501)$ were receiving ART, $67.9 \%(n=1746)$ reported undetectable viral load, and $46.0 \%$ $(\mathrm{n}=1181)$ reported their CD4+ T cell count level to be above $500 / \mu \mathrm{L}$. Less than $5 \%$ of the participants self-reported having severe AIDS-related symptoms (Tables 1 and 2). 
Table 1. Sociodemographic characteristics of 2570 unvaccinated people living with HIV and AIDS in eight Chinese cities.

\begin{tabular}{lllll}
\hline Characteristic & $\begin{array}{l}\text { All participants } \\
(\mathrm{N}=2570), \mathrm{n}\end{array}$ & $\begin{array}{l}\text { Participants willing to receive } \\
\text { COVID-19 vaccination }\end{array}$ & $\begin{array}{l}\text { Participants unwilling to receive } \\
\text { COVID-19 vaccination }\end{array}$ & $\begin{array}{l}\text { Participants willing } \\
\text { versus unwilling, }\end{array}$ \\
& $(\%)$ & $(\mathrm{n}=1470), \mathrm{n}(\%)$ & $(\mathrm{n}=1100), \mathrm{n}(\%)$ & $\mathrm{COR}^{\mathrm{a}}(95 \% \mathrm{CI})$
\end{tabular}

\section{Age group (years)}

\begin{tabular}{|c|c|c|c|c|c|}
\hline $18-29$ & $791(30.8)$ & $456(31.0)$ & $335(30.5)$ & 1.0 & $\operatorname{Ref}^{b}$ \\
\hline $30-39$ & 1125 (43.8) & $638(43.4)$ & $487(44.3)$ & $0.96(0.80-1.16)$ & .68 \\
\hline $40-49$ & 475 (18.5) & $287(19.5)$ & $188(17.1)$ & $1.12(0.89-1.41)$ & .33 \\
\hline$\geq 50$ & $179(7.0)$ & $89(6.1)$ & $90(8.2)$ & $0.73(0.53-1.01)$ & .054 \\
\hline
\end{tabular}

\section{Gender at birth}

\section{Male \\ Female}

Gender identity

Male
Female
Transgender
Others

\section{Relationship status}

Currently single

Cohabitating or married

with a same-sex partner

Cohabitating or married with an opposite-sex partner

$\begin{array}{ll}2431(94.6) & 1390(94.6) \\ 139(5.4) & 80(5.4) \\ 2106(81.9) & 1224(83.3) \\ 228(8.9) & 127(8.6) \\ 228(8.9) & 114(7.8) \\ 8(0.3) & 5(0.3)\end{array}$

$\begin{array}{ll}1750(68.1) & 993(67.6) \\ 377(14.7) & 217(14.8) \\ 443(17.2) & 260(17.7)\end{array}$

\section{Highest education level attained}

Junior high school or below

Senior high school or equiv- 574 (22.3)

alent

College and above

$1571(61.1)$

249 (16.9)

319 (21.7)

902 (61.4)

Employment status

Full time
Part time, unemployed, re-
tired, student, or others

1782 (69.3)

$1022(69.5)$

448 (30.5)

Monthly personal income (Chinese yuan ${ }^{c}$ )

No fixed income
$<1000$
$1000-2999$
$3000-4999$
$5000-6999$
$7000-9999$
$\geq 10,000$

Type of health insurance

$\begin{array}{lll}\text { None } & 307(11.9) & 166(11.3) \\ \text { Basic health insurance only } & 1927(75.0) & 1111(75.6) \\ \begin{array}{l}\text { Commercial health insur- } \\ \text { ance only }\end{array} & 69(2.7) & 47(3.2)\end{array}$

$\begin{array}{ll}302(11.8) & 174(11.8) \\ 136(5.3) & 72(4.9) \\ 338(13.2) & 199(13.5) \\ 736(28.6) & 413(28.1) \\ 492(19.1) & 285(19.4) \\ 273(10.6) & 174(11.8) \\ 293(11.4) & 153(10.4)\end{array}$

$128(11.8)$

64 (5.8)

139 (12.6)

323 (29.4)

207 (18.8)

99 (9.0)

140 (12.7)

141 (12.8)

816 (74.2)

$22(2.0)$

$\begin{array}{ll}1.0 & \text { Ref } \\ 1.02(0.72-1.44) & .93\end{array}$

1.0

Ref

$0.91(0.69-1.19) \quad$ 48

$0.72(0.55-0.95) \quad .02$

$1.20(0.29-5.04) \quad .80$

$\begin{array}{ll}1.0 & \text { Ref } \\ 1.03(0.83-1.30) & .77 \\ 1.08(0.88-1.34) & .46\end{array}$

1.0

Ref

$0.88(0.69-1.14) \quad .34$

$0.95(0.77-1.18) \quad .66$

1.0

Ref

$0.98(0.83-1.16) \quad .81$

1.0

Ref

$0.83(0.55-1.24) \quad .36$

$1.05(0.77-1.44) \quad .75$

$0.94(0.72-1.23) \quad .66$

$1.01(0.76-1.35) \quad .93$

$1.29(0.92-1.81) \quad .13$

$0.80(0.58-1.11) \quad .19$ 


\begin{tabular}{lllll}
\hline Characteristic & $\begin{array}{l}\text { All participants } \\
(\mathrm{N}=2570), \mathrm{n} \\
(\%)\end{array}$ & $\begin{array}{l}\text { Participants willing to receive } \\
\text { COVID-19 vaccination } \\
(\mathrm{n}=1470), \mathrm{n}(\%)\end{array}$ & $\begin{array}{l}\text { Participants unwilling to receive } \\
\text { COVID-19 vaccination } \\
(\mathrm{n}=1100), \mathrm{n}(\%)\end{array}$ & $\begin{array}{l}\text { Participants willing } \\
\text { versus unwilling, } \\
\mathrm{cOR}^{\mathrm{a}}(95 \% \mathrm{CI})\end{array}$ \\
\hline $\begin{array}{l}\text { Both basic and commercial } \\
\text { health insurance } \\
\text { Others }\end{array}$ & $253(9.8)$ & $140(9.5)$ & $8(10.3)$ & $1.05(0.75-1.47)$ \\
.77 \\
\hline
\end{tabular}

${ }^{\mathrm{a}} \mathrm{cOR}$ : crude odds ratio.

${ }^{b}$ Ref: reference.

${ }^{\mathrm{c}} \mathrm{A}$ currency exchange rate of 1 Chinese yuan $=\mathrm{US} \$ 0.16$ is applicable. 
Table 2. Lifestyle and health conditions of 2570 unvaccinated people living with HIV and AIDS in eight Chinese cities.

\begin{tabular}{lllll}
\hline Condition & All participants & Participants willing to & Participants unwilling & Participants willing $P$ value \\
& receive COVID-19 & to receive COVID-19 & versus unwilling, cOR \\
& vaccination $(\mathrm{n}=1470)$, & vaccination $(\mathrm{n}=1100)$, & $(95 \% \mathrm{CI})$ \\
$\mathrm{n}(\%)$ & $\mathrm{n}(\%)$ &
\end{tabular}

\section{Current smoker}

$\begin{array}{llllll}\text { No } & 1855(72.2) & 1069(72.7) & 786(71.5) & 1.0 & \text { Ref }^{\mathrm{b}} \\ \text { Yes } & 715(27.8) & 401(27.3) & 314(28.5) & 0.94(0.79-1.12) & .48\end{array}$

\section{Current drinker}

$\begin{array}{llllll}\text { No } & 2068(80.5) & 1190(81.0) & 878(79.8) & 1.0 & \text { Ref } \\ \text { Yes } & 502(19.5) & 280(19.0) & 222(20.2) & 0.93(0.77-1.13) & .47\end{array}$

Self-reported BMI $\left(\mathrm{kg} / \mathrm{m}^{2}\right)$

$\begin{array}{llllll}<18.5 & 235(9.1) & 125(8.5) & 110(10.0) & 1.0 & \text { Ref } \\ 18.5-23.9 & 1649(64.2) & 944(64.2) & 705(64.1) & 1.18(0.90-1.55) & .24 \\ 24.0-27.9 & 558(21.7) & 327(22.2) & 231(21.0) & 1.25(0.92-1.69) & .16 \\ \geq 28 & 127(4.9) & 74(5.0) & 53(4.8) & 1.23(0.80-1.90) & .36\end{array}$

Presence of chronic disease conditions

$\begin{array}{ll}\text { No } & 1707(66.4) \\ \text { Yes } & 863(33.6)\end{array}$

$$
1009 \text { (68.6) }
$$

698 (63.5)

1.0

Ref

461 (31.4)

402 (36.5)

$0.79(0.67-0.94)$

.01

Medication use for treating chronic diseases

$\begin{array}{ll}\text { No } & 2411(93.8) \\ \text { Yes } & 159(6.2)\end{array}$

$1385(94.2)$

$85(5.8)$

$1026(93.3)$

$74(6.7)$

1.0

$0.85(0.62-1.17)$

Ref

.33

History of other vaccinations in the past 3 years

$\begin{array}{ll}\text { No } & 2002(77.9) \\ \text { Yes } & 568(22.1)\end{array}$

$1110(75.5)$

$892(81.1)$

1.0

$1.39(1.15-1.69)$

Ref

208 (18.9)

$264(18.0)$

$179(16.3)$

513 (46.6)

$408(37.1)$

$$
443 \text { (17.2) }
$$

685 (46.6)

$521(35.4)$

$929(36.1)$

29 (2.6)

1071 (97.4)

1.0

$0.91(0.73-1.13)$

0.87 (0.69-1.09)

.001

Receiving antiretroviral therapy
40 (2.7)
1430 (97.3)
No
69 (2.7)
2501 (97.3)

HIV viral load in the most recent episode of testing (copies/mL)

$\begin{array}{lll}\text { Undetectable }(<50) & 1746(67.9) & 988(67.2) \\ 50-200 & 154(6.0) & 79(5.4) \\ 201-400 & 69(2.7) & 45(3.1) \\ >400 & 137(5.3) & 87(5.9) \\ \text { Not sure } & 464(18.1) & 271(18.4)\end{array}$

CD4+ T cell count in the most recent episode of testing (cells $/ \mathrm{mm}^{3}$ )

$\begin{array}{llll}\geq 500 & 1181(46.0) & 669(45.5) & 512(46.5) \\ 350-499 & 531(20.7) & 320(21.8) & 211(19.2) \\ 200-349 & 258(10.0) & 150(10.2) & 108(9.8) \\ <200 & 89(3.5) & 44(3.0) & 45(4.1) \\ \text { Unknown } & 511(19.9) & 287(19.5) & 224(20.4)\end{array}$

$758(68.9)$
$75(6.8)$
$24(2.2)$
$50(4.5)$
$193(17.5)$

1.0

$0.97(0.60-1.57)$

Ref

.90

Ref

.38

.22 


\begin{tabular}{|c|c|c|c|c|c|}
\hline Condition & $\begin{array}{l}\text { All participants } \\
(\mathrm{N}=2570), \mathrm{n}(\%)\end{array}$ & $\begin{array}{l}\text { Participants willing to } \\
\text { receive COVID-19 } \\
\text { vaccination }(\mathrm{n}=1470) \text {, } \\
\mathrm{n}(\%)\end{array}$ & $\begin{array}{l}\text { Participants unwilling } \\
\text { to receive COVID-19 } \\
\text { vaccination ( } \mathrm{n}=1100) \text {, } \\
\mathrm{n}(\%)\end{array}$ & $\begin{array}{l}\text { Participants willing } \\
\text { versus unwilling, cOR } \\
(95 \% \mathrm{CI})\end{array}$ & $P$ value \\
\hline \multicolumn{6}{|c|}{ Self-reported severity of AIDS-related symptoms } \\
\hline No symptoms & $1306(50.8)$ & $767(52.2)$ & $539(49.0)$ & 1.0 & Ref \\
\hline Mild & $839(32.6)$ & $483(32.9)$ & $356(32.4)$ & $0.95(0.80-1.14)$ & .60 \\
\hline Moderate & $308(12.0)$ & $157(10.7)$ & $151(13.7)$ & $0.73(0.57-0.94)$ & .01 \\
\hline Severe & 117 (4.6) & $63(4.3)$ & $54(4.9)$ & $0.82(0.56-1.20)$ & .31 \\
\hline
\end{tabular}

a cOR: crude odds ratio.

${ }^{b}$ Ref: reference.

\section{Willingness to Receive COVID-19 Vaccination and Variables at the Individual, Interpersonal, and Sociostructural Levels}

Over half of the participants were willing to receive free COVID-19 vaccinations in the future (1470/2570, 57.2\%). A shortage of COVID-19 vaccines was encountered in Shenyang,
Guangzhou, and Shenzhen. Among the participants, 19.0\% (488/2570) identified themselves as belonging to a priority group that would receive COVID-19 vaccination. The Cronbach $\alpha$ of the scales for perceptions related to COVID-19 vaccination ranged from .83 to .92 ; single factors were identified by exploratory factor analysis, explaining $61.1 \%$ to $76.4 \%$ of the total variance (Table 3 and Multimedia Appendix 1). 
Table 3. Willingness to receive COVID-19 vaccination and variables at the sociostructural, individual, and interpersonal levels among 2570 unvaccinated people living with HIV and AIDS (PLWHA).

\begin{tabular}{|c|c|c|c|c|c|}
\hline Variable & $\begin{array}{l}\text { All participants } \\
(\mathrm{N}=2570)\end{array}$ & $\begin{array}{l}\text { Participants willing to } \\
\text { receive COVID-19 } \\
\text { vaccination }(n=1470)\end{array}$ & $\begin{array}{l}\text { Participants unwilling } \\
\text { to receive COVID-19 } \\
\text { vaccination ( } n=1100)\end{array}$ & $\begin{array}{l}\text { Participants willing } \\
\text { versus unwilling, } \mathrm{cOR}^{\mathrm{a}} \\
(95 \% \mathrm{CI})\end{array}$ & $P$ value \\
\hline \multicolumn{6}{|c|}{ Willing to receive free COVID-19 vaccination, $\mathrm{n}(\%)$} \\
\hline $\begin{array}{l}\text { No (very unlikely, unlikely, } \\
\text { or neutral) }\end{array}$ & $1100(42.8)$ & $0(0)$ & $1100(100)$ & $\mathrm{N} / \mathrm{A}^{\mathrm{b}}$ & N/A \\
\hline Yes (likely or very likely) & $1470(57.2)$ & $1470(100)$ & $0(0)$ & N/A & N/A \\
\hline
\end{tabular}

Sociostructural-level variables, $\mathbf{n}(\%)$

Individuals could make an appointment to receive COVID-19 vaccination during the study period

$\begin{array}{llllll}\text { No } & 1578(61.4) & 887(60.3) & 691(62.8) & 1.0 & \operatorname{Ref}^{\mathrm{c}} \\ \text { Yes } & 992(38.6) & 583(39.7) & 409(37.2) & 1.11(0.95-1.30) & .20\end{array}$

There was a shortage of COVID-19 vaccine in the city where the participants were living during the study period

$\begin{array}{llllll}\text { No } & 1729(67.3) & 1009(68.6) & 720(65.5) & 1.0 & \text { Ref } \\ \text { Yes } & 841(32.7) & 461(31.4) & 380(34.5) & 0.87(0.73-1.02) & .09\end{array}$

Participants belonged to priority groups that would receive COVID-19 vaccination in their cities during the study period

$\begin{array}{llllll}\text { No } & 2082(81.0) & 1189(80.9) & 893(81.2) & 1.0 & \text { Ref } \\ \text { Yes } & 488(19.0) & 281(19.1) & 207(18.8) & 1.02(0.84-1.25) & .85\end{array}$

Individual-level variables: perceptions and attitudes toward COVID-19 vaccination, mean (SD)

\begin{tabular}{|c|c|c|c|c|c|}
\hline Positive Attitude Scale ${ }^{\mathrm{d}}$ score & $18.4(4.8)$ & $19.3(4.6)$ & $17.1(4.7)$ & $1.11(1.09-1.13)$ & $<.001$ \\
\hline $\begin{array}{l}\text { Negative Attitude Scale } \\
\text { score }\end{array}$ & $18.6(5.2)$ & $18.1(5.4)$ & $19.3(4.8)$ & $0.96(0.94-0.97)$ & $<.001$ \\
\hline $\begin{array}{l}\text { Perceived Subjective Norm } \\
\text { Scale }^{f} \text { score }\end{array}$ & $13.3(2.4)$ & $14.5(2.5)$ & $12.3(1.8)$ & $1.53(1.46-1.61)$ & $<.001$ \\
\hline $\begin{array}{l}\text { Perceived Behavioral Control } \\
\text { Scale }^{\mathrm{g}} \text { score }\end{array}$ & $12.9(6.1)$ & $14.7(6.1)$ & $10.6(5.4)$ & $1.13(1.11-1.14)$ & $<.001$ \\
\hline terpersonal-level variables, me & an (SD) & & & & \\
\hline $\begin{array}{l}\text { Advice from doctors regard- } \\
\text { ing COVID-19 vaccination }\end{array}$ & $2.1(0.5)$ & $2.2(0.5)$ & $2.0(0.4)$ & $2.03(1.69-2.44)$ & $<.001$ \\
\hline $\begin{array}{l}\text { Advice from } \mathrm{CBO}^{\mathrm{h}} \text { staff re- } \\
\text { garding COVID-19 vaccina- } \\
\text { tion }\end{array}$ & $2.1(0.4)$ & $2.1(0.4)$ & $2.0(0.4)$ & $1.86(1.49-2.32)$ & $<.001$ \\
\hline $\begin{array}{l}\text { Advice from friends and/or } \\
\text { family members regarding } \\
\text { COVID-19 vaccination }\end{array}$ & $2.0(0.2)$ & $2.0(0.4)$ & $1.9(0.2)$ & $3.18(1.92-5.26)$ & $<.001$ \\
\hline $\begin{array}{l}\text { Advice from other PLWHA } \\
\text { regarding COVID-19 vaccina- } \\
\text { tion }\end{array}$ & $2.0(0.3)$ & $2.1(0.3)$ & $1.9(0.4)$ & $2.38(1.85-3.07)$ & $<.001$ \\
\hline $\begin{array}{l}\text { Overall opinion regarding } \\
\text { COVID-19 vaccination for } \\
\text { PLWHA on the internet and } \\
\text { social media }\end{array}$ & $2.0(0.4)$ & $2.1(0.4)$ & $2.0(0.4)$ & $1.63(1.34-1.98)$ & $<.001$ \\
\hline
\end{tabular}

a cOR: crude odds ratio.

${ }^{\mathrm{b}} \mathrm{N} / \mathrm{A}$ : not applicable; cOR was not calculated for this item.

${ }^{\mathrm{c}}$ Ref: reference.

${ }^{d}$ The Positive Attitude Scale includes five items and has a maximum score of 25; Cronbach $\alpha=.83$; one factor was identified by exploratory factor analysis, explaining $61.1 \%$ of the total variance.

${ }^{\mathrm{e}}$ The Negative Attitude Scale includes five items and has a maximum score of 25 ; Cronbach $\alpha=.87$; one factor was identified by exploratory factor analysis, explaining $66.3 \%$ of the total variance. 
${ }^{f}$ The Perceived Subjective Norm Scale includes four items and has a maximum score of 20; Cronbach $\alpha=.84$; one factor was identified by exploratory factor analysis, explaining $63.4 \%$ of the total variance.

${ }^{g}$ The Perceived Behavioral Control Scale includes five items and has a maximum score of 25 ; Cronbach $\alpha=.92$; one factor was identified by exploratory factor analysis, explaining $76.4 \%$ of the total variance.

${ }^{\mathrm{h}} \mathrm{CBO}$ : community-based organization.

\section{Factors Associated With Willingness to Receive COVID-19 Vaccination}

In the univariate logistic regression analysis, transgender persons, those with chronic conditions, and those with more severe AIDS-related symptoms showed lower willingness to receive COVID-19 vaccination. Having commercial health insurance only and a history of other vaccinations in the past 3 years were associated with higher willingness to receive COVID-19 vaccination (Tables 1 and 2).

After adjusting for significant background characteristics, having more positive attitudes toward COVID-19 vaccination (aOR $1.11,95 \%$ CI 1.09-1.12; $P<.001$ ), stronger perceived support from significant others (perceived subjective norm; aOR 1.53, 95\% CI 1.46-1.61; $P<.001$ ), and higher perceived behavioral control (aOR 1.13, 95\% CI 1.11-1.14; $P<.001$ ) to take up the vaccination were associated with higher willingness to receive COVID-19 vaccination. A negative association was found between negative attitudes toward COVID-19 vaccination and the dependent variable (aOR 0.96, 95\% CI 0.94-0.97; $P<.001$ ). At the interpersonal level, receiving advice supportive of COVID-19 vaccination from doctors (aOR 1.99, 95\% CI $1.65-2.40 ; P<.001$ ), CBO staff (aOR 1.89, 95\% CI 1.51-2.36; $P<.001$ ), friends and/or family members (aOR $3.22,95 \% \mathrm{CI}$ $1.93-5.35 ; P<.001$ ), and other PLWHA (aOR 2.38, 95\% CI $1.85-3.08 ; P<.001)$ were associated with higher willingness to receive COVID-19 vaccination. The overall opinion supporting COVID-19 vaccination for PLWHA on the internet and social media was also positively associated with the dependent variable (aOR 1.59, 95\% CI 1.31-1.94; $P<.001$; Table 4).

Table 4. Factors associated with willingness to receive COVID-19 vaccination among 2570 unvaccinated people living with HIV and AIDS (PLWHA).

\begin{tabular}{lll}
\hline Variable & aOR $^{\mathrm{a}}(95 \% \mathrm{CI})$ & $P$ value \\
\hline
\end{tabular}

Sociostructural-level variables

Individuals could make an appointment to receive COVID-19 vaccination during the study period

$\begin{array}{lll}\text { No } & \text { N/A } & \text { N/A } \\ \text { Yes } & \text { N/A } & \text { N/A }\end{array}$

There was a shortage of COVID-19 vaccines in the city where the participants were living during the study period No N/A $\quad$ N/A

Yes $\quad$ N/A N/A

Participants belonged to priority groups that would receive COVID-19 vaccination in their cities during the study period

$\begin{array}{lll}\text { No } & \text { N/A } & \text { N/A } \\ \text { Yes } & \text { N/A } & \text { N/A }\end{array}$

Individual-level variables

Positive Attitude Scale score

$1.11(1.09-1.12) \quad<.001$

Negative Attitude Scale score

$0.96(0.94-0.97) \quad<.001$

Perceived Subjective Norm Scale score

$1.53(1.46-1.61) \quad<.001$

Perceived Behavioral Control Scale score

$1.13(1.11-1.14) \quad<.001$

Interpersonal-level variables

Advice from doctors regarding COVID-19 vaccination

$1.99(1.65-2.40) \quad<.001$

Advice from $\mathrm{CBO}^{\mathrm{c}}$ staff regarding COVID-19 vaccination

$1.89(1.51-2.36) \quad<.001$

Advice from friends and/or family members regarding COVID-19 vaccination

$3.22(1.93-5.35)$

$<.001$

Advice from other PLWHA regarding COVID-19 vaccination

$2.38(1.85-3.08)$

$<.001$

Overall opinion regarding COVID-19 vaccination for PLWHA on the internet and

$1.59(1.31-1.94)$

$<.001$

social media

$\mathrm{a}_{\mathrm{aOR}}$ : adjusted odds ratio; odds ratios were obtained by fitting a single logistic regression model involving an independent variable of interest and all background variables listed in Tables 1 and 2 with $P<.05$ in univariate analysis.

${ }^{\mathrm{b}}$ Univariate analyses of these variables yielded $P>.05$, so multivariate analyses were not conducted.

${ }^{\mathrm{c}} \mathrm{CBO}$ : community-based organization. 
Testing the Mediation Effects of Perceptions on the Association Between Interpersonal-Level Variables and Willingness to Receive COVID-19 Vaccination

\section{Model Testing}

Confirmative factor analysis showed that perceptions fit the data well $(\mathrm{CFI}=0.98$, TLI $=0.90$, and RMSEA $=0.08)$. All the factor loadings were significant at $P<.001$, with $\beta$ ranging from .23 to .73 . The interpersonal-level variables also fit the data well $(\mathrm{CFI}=0.98$, TLI $=0.97$, and RMSEA $=0.02)$. All the factor loadings were significant at $P<.001$, with standardized coefficients ranging from .27 to .50 . The hypothesized mediation model showed good fit to the data $(\mathrm{CFI}=0.96$, TLI $=0.94$, and RMSEA=0.03).

\section{Path Coefficients}

Path analysis showed that interpersonal-level variables were positively associated with perceptions $(\mathrm{B}=4.72, \beta=.57, P<.001)$, while their association with willingness to receive COVID-19 vaccination was nonsignificant $(\mathrm{B}=-0.28, \beta=-.06, P=.23)$. Perceptions were positively associated with willingness to receive COVID-19 vaccination ( $\mathrm{B}=0.43, \beta=.74, P<.001$; Figure $5)$.

Figure 5. Mediation model with path coefficients. CBO: community-based organization; PLWHA: people living with HIV and AIDS.

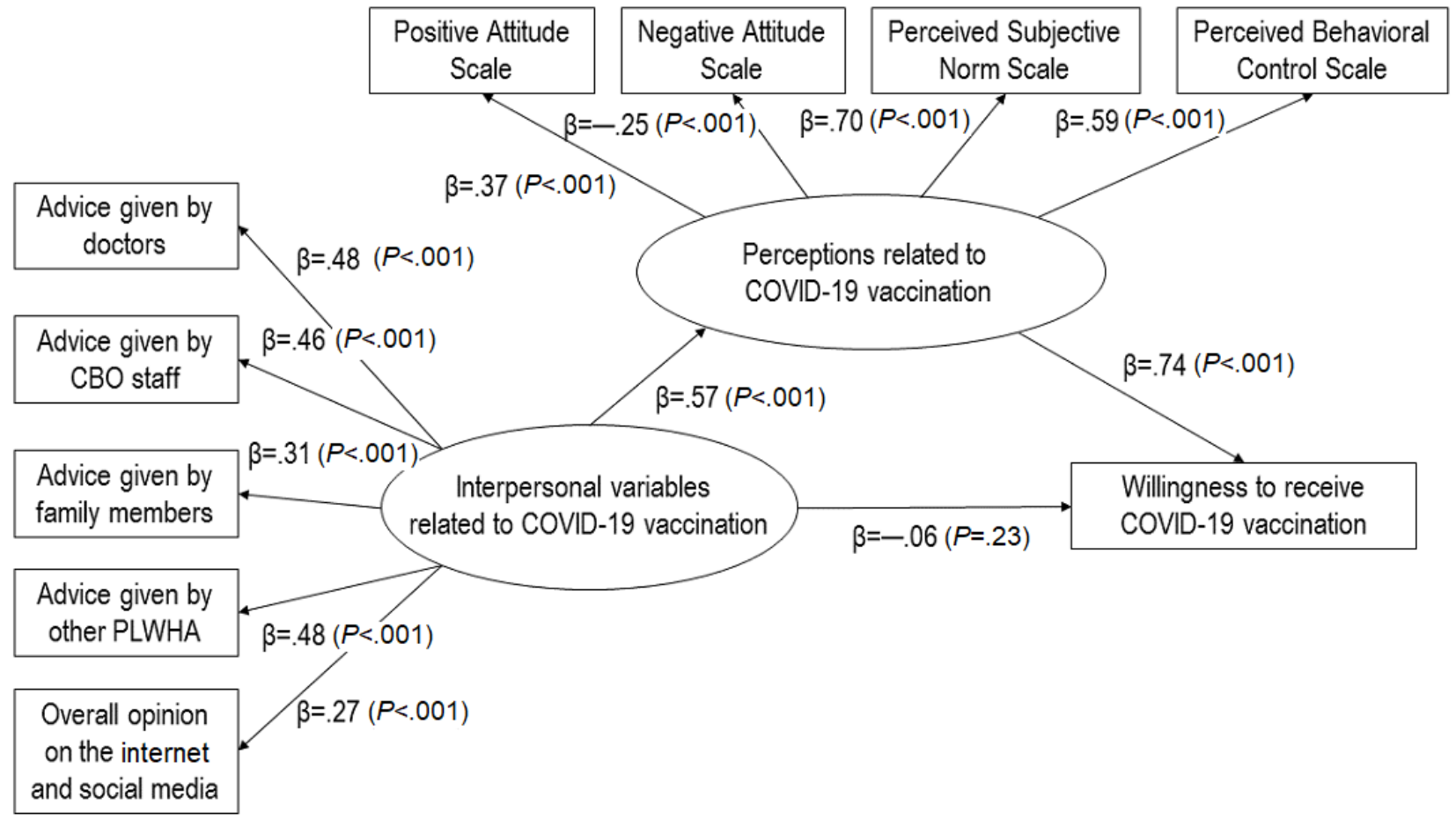

\section{Mediation Effects}

Bootstrap analysis showed that interpersonal-level variables $(\mathrm{B}=2.01,95 \%$ CI $1.67-2.53 ; \beta=.43,95 \%$ CI $.37-.51 ; P<.001)$ were indirectly associated with willingness to receive COVID-19 vaccination via perceptions. Perceptions fully mediated the association between interpersonal-level variables and willingness to receive COVID-19 vaccination.

\section{Discussion}

\section{Principal Findings}

We found that willingness to receive COVID-19 vaccination among PLWHA is essential in the scale-up of COVID-19 vaccination among this group. The finding represents the latest estimate of willingness to receive COVID-19 vaccination among PLWHA in China and can be used to project future vaccine uptake in this group. We extended the existing literature by conducting this study in multiple cities in different geographic regions of China, with a large sample size, and examined the multiple-level factors that correlated with willingness to receive the vaccine.
We found that the level of willingness among our participants was relatively low $(<60 \%)$. This level was lower than that of PLWHA in France and the United States as well as the general population in most parts of the world [19] and China (70\%-90\%) $[26,27]$. Since there is a gap between willingness and actual uptake, COVID-19 vaccination coverage among PLWHA would be even lower without effective interventions [32]. The above findings revealed COVID-19 vaccination hesitancy and highlighted a strong need to promote COVID-19 vaccination among PLWHA.

This study examined associated factors at all three levels suggested by the socioecological model; the findings could inform tailored interventions promoting COVID-19 vaccination among PLWHA. This was the first study to demonstrate that the individual-level variables (ie, perceptions related to COVID-19 vaccination) and interpersonal-level variables (ie, advice from others and information exposure on the internet and social media) were determinants of willingness among PLWHA. The findings extended the application of the socioecological model. More importantly, this study examined the potential mechanism of the associations between 
interpersonal interactions and willingness to receive COVID-19 vaccination. The results suggest that exposure to advice and information supporting PLWHA in receiving COVID-19 vaccination might enhance perceptions favoring COVID-19 vaccination, which, in turn, may increase their willingness to receive such vaccination. The significant mediation effect supported the mechanism proposed by the social learning theory [33].

This study also had numerous practical implications for developing tailored vaccination strategies for PLWHA. First, more attention should be given to PLWHA who are transgender persons, with chronic conditions, and who have severe AIDS-related symptoms, as these subgroups reported lower willingness. Transgender people are often marginalized, encountering difficulties to access health care services [34] Future programs targeting PLWHA should consider including transgender-friendly vaccination services. Having AIDS-related symptoms was also associated with lower willingness. Since official opinions in China stated that the effectiveness of COVID-19 vaccination was lower for people with immunodeficiency [18], PLWHA might think that they may not benefit from COVID-19 vaccination. Health communication messages should clearly state that it is recommended that PLWHA receive COVID-19 vaccination if their chronic conditions are stable, regardless of AIDS-related symptoms.

Second, modifying perceptions related to COVID-19 vaccination is potentially useful in health promotion, as they were significantly associated with willingness in the expected directions. It is useful to increase positive attitudes toward COVID-19 vaccination, as this was a facilitator. Health communication messages should emphasize the physical and psychological benefits of COVID-19 vaccination. About half of the participants had concerns related to side effects, exposing PLWHA's identities, and potential interactions between COVID-19 vaccines and HIV and ART. Having more concerns was associated with lower willingness. Testimonials on positive experiences shared by vaccinated PLWHA might be useful in reducing their concerns related to side effects and privacy. Health communication messages should also emphasize that there is no evidence showing that ART and COVID-19 vaccination would have negative impacts on each other [35]. Less than $40 \%$ of the participants perceived that medical professionals, CBO staff, family members, and friends would support them in taking up COVID-19 vaccination. Such perception was also a facilitator. Future programs should consider involving the significant others of PLWHA in order to create a subjective norm favoring COVID-19 vaccination uptake. It is also useful to enhance perceived behavioral control, as this was another facilitator. There is much room for improvement. Facilitating PLWHA in forming a plan to receive COVID-19 vaccination may be helpful for improving perceived behavioral control.

Third, the significant mediation effect of perceptions on the association between interpersonal-level variables and willingness to receive COVID-19 vaccination suggested that future programs should involve clinical doctors, CBO staff, friends and/or family members, and peers of PLWHA to give supportive advice. Health authorities should also disseminate clear recommendations for PLWHA to receive COVID-19 vaccination through official online channels, which are considered influential and credible sources by Chinese people [36]. These strategies may be useful to modify PLWHA's perceptions and, in turn, increase their willingness to receive COVID-19 vaccination.

This study also had some limitations. First, policies and guidelines related to COVID-19 vaccination are changing rapidly. Our findings are most applicable to the early phase of COVID-19 vaccination implementation in China. Second, participants were recruited in large Chinese cities. Generalizations to PLWHA living in smaller cities or counties in China should be made cautiously. Third, we were not able to collect information from PLWHA who refused to participate in the study. PLWHA who refused to complete the survey may have different characteristics from the participants. Selection bias existed. Fourth, most items and scales used in this study were self-constructed based on those used in the general population. The internal validity of these scales was acceptable. However, external validation data were seldom available. Fifth, it was a limitation that we did not ask whether participants anticipated or had experienced challenges in making an appointment to receive the COVID-19 vaccine. The procedures to make an appointment are easy. Most Chinese people did not encounter difficulties when they were using the appointment system. We believe that the impact of anticipated and experienced challenges in making an appointment on PLWHA's willingness to receive COVID-19 vaccination was limited. Sixth, we did not study PLWHA's preferences for different types of COVID-19 vaccines. Although inactivated vaccines were the only available COVID-19 vaccines in China during the study period, it is worthwhile to look at their preferences for other types of vaccines (eg, mRNA or adenovirus vector vaccines) [37]. Moreover, the selection of the time frame for the history of other vaccinations (ie, past 3 years) was arbitrary. Furthermore, causality could not be established, as this was a cross-sectional study.

\section{Conclusions}

In sum, PLWHA in China reported a relatively low willingness to receive COVID-19 vaccination compared to PLWHA in other countries and the general population in most parts of the world. Perceptions related to COVID-19 vaccination and interpersonal-level variables, such as receiving advice from others or information exposure through the internet and social media, were determinants of willingness. Information exposure on the internet and social media and interpersonal communications with doctors, CBO staff, friends, family members, and other PLWHA may be major sources of influence on PLWHA's perceptions and willingness to receive COVID-19 vaccination. The study findings could be used to design tailored interventions with the aims of improving vaccination coverage and reduce risks of COVID-19 among PLWHA. 


\section{Acknowledgments}

We would like to thank all participants in this study and the staff who contributed during the data collection process. We are also thankful to Changzhi Medical College and the National Institute of Mental Health of the National Institutes of Health for funding this project. This study was funded the Academic Technology Leader Project of Changzhi Medical College (grant XSQ201902) and the National Institute of Mental Health of the National Institutes of Health (grant R34MH119963). The funders had no role in the study design; the collection, analysis, or interpretation of the data; writing of the manuscript; or the decision to submit the paper for publication.

\section{Authors' Contributions}

WT, ZW, and JX were responsible for the conceptualization of the study. HZQ, WT, and JX were responsible for the methodology of the study. XH, MY, GF, GL, LL, JY, YQ, and JZ were responsible for data curation. ZW and HJ were responsible for the formal analysis. XH, MY, GF, GL, LL, JY, YQ, JZ, XZ, XJ, GC, and JX were responsible for project administration and for securing resources. JX was responsible for supervision. $\mathrm{ZW}, \mathrm{HJ}$, and JX were responsible for writing and preparing the original draft of the paper. HZQ, WT, ZW, and JX were responsible for writing, reviewing, and editing the paper. JX was responsible for funding acquisition. All authors have read and agreed to submission of the manuscript. XH, MY, GF, GL, LL, JY, YQ, and JZ contributed equally as first authors; WT, ZW, and JX contributed equally as corresponding authors.

\section{Conflicts of Interest}

None declared.

\section{Multimedia Appendix 1}

Frequency distribution of items measuring individual-level and interpersonal-level variables. [DOCX File, $20 \mathrm{~KB}-$ Multimedia Appendix 1]

\section{References}

1. Coronavirus disease (COVID-19): COVID-19 vaccines and people living with HIV. World Health Organization. 2021 Jul 14. URL: https://www.who.int/news-room/q-a-detail/ coronavirus-disease-(covid-19)-covid-19-vaccines-and-people-living-with-hiv [accessed 2021-10-06]

2. Bartsch SM, O'Shea KJ, Ferguson MC, Bottazzi ME, Wedlock PT, Strych U, et al. Vaccine efficacy needed for a COVID-19 coronavirus vaccine to prevent or stop an epidemic as the sole intervention. Am J Prev Med 2020 Oct;59(4):493-503 [FREE Full text] [doi: 10.1016/j.amepre.2020.06.011] [Medline: 32778354]

3. Polack FP, Thomas SJ, Kitchin N, Absalon J, Gurtman A, Lockhart S, C4591001 Clinical Trial Group. Safety and efficacy of the BNT162b2 mRNA Covid-19 vaccine. N Engl J Med 2020 Dec 31;383(27):2603-2615 [FREE Full text] [doi: 10.1056/NEJMoa2034577] [Medline: 33301246]

4. Voysey M, Clemens S, Madhi S, Weckx L, Folegatti P, Aley P, Oxford COVID Vaccine Trial Group. Safety and efficacy of the ChAdOx1 nCoV-19 vaccine (AZD1222) against SARS-CoV-2: An interim analysis of four randomised controlled trials in Brazil, South Africa, and the UK. Lancet 2021 Jan 09;397(10269):99-111 [FREE Full text] [doi: 10.1016/S0140-6736(20)32661-1] [Medline: 33306989]

5. Baden LR, El Sahly HM, Essink B, Kotloff K, Frey S, Novak R, COVE Study Group. Efficacy and safety of the mRNA-1273 SARS-CoV-2 vaccine. N Engl J Med 2021 Feb 04;384(5):403-416 [FREE Full text] [doi: 10.1056/NEJMoa2035389] [Medline: 33378609]

6. Sadoff J, Gray G, Vandebosch A, Cárdenas V, Shukarev G, Grinsztejn B, ENSEMBLE Study Group. Safety and efficacy of single-dose Ad26.COV2.S vaccine against Covid-19. N Engl J Med 2021 Jun 10;384(23):2187-2201 [FREE Full text] [doi: 10.1056/NEJMoa2101544] [Medline: 33882225]

7. Shinde V, Bhikha S, Hoosain Z, Archary M, Bhorat Q, Fairlie L, 2019nCoV-501 Study Group. Efficacy of NVX-CoV2373 Covid-19 vaccine against the B.1.351 variant. N Engl J Med 2021 May 20;384(20):1899-1909 [FREE Full text] [doi: 10.1056/NEJMoa2103055] [Medline: 33951374]

8. Hosein SR. Encouraging results from the Pfizer-BioNTech COVID-19 vaccine in HIV-positive people. CATIE. 2021 May 25. URL: https://www.catie.ca/en/catienews/2021-05-25/ encouraging-results-pfizer-biontech-covid-19-vaccine-hiv-positive-people [accessed 2021-10-06]

9. Ruddy J, Boyarsky B, Bailey J, Karaba A, Garonzik-Wang J, Segev D, et al. Safety and antibody response to two-dose SARS-CoV-2 messenger RNA vaccination in persons with HIV. AIDS 2021 Jul 08. [doi: 10.1097/QAD.0000000000003017] [Medline: 34261097 ]

10. Woldemeskel B, Karaba A, Garliss C, Beck E, Wang K, Laeyendecker O, et al. The BNT162b2 mRNA vaccine elicits robust humoral and cellular immune responses in people living with HIV. Clin Infect Dis 2021 Jul 22:1-3 [FREE Full text] [doi: 10.1093/cid/ciab648] [Medline: 34293114] 
11. Frater J, Ewer KJ, Ogbe A, Pace M, Adele S, Adland E, Oxford COVID Vaccine Trial Group. Safety and immunogenicity of the ChAdOx1 nCoV-19 (AZD1222) vaccine against SARS-CoV-2 in HIV infection: A single-arm substudy of a phase 2/3 clinical trial. Lancet HIV 2021 Aug;8(8):e474-e485 [FREE Full text] [doi: 10.1016/S2352-3018(21)00103-X] [Medline: 34153264]

12. Madhi S, Koen A, Fairlie L, Cutland C, Ballie V, Padayachee S. ChAdOx1 nCoV-19 (AZD1222) vaccine in people living with and without HIV. Research Square. Preprint published on March 17, 2021 [FREE Full text] [doi: 10.21203/rs.3.rs-322470/v1]

13. United States Department of Health and Human Services. Guidance for COVID-19 and people with HIV. Guidelines for the Prevention and Treatment of Opportunistic Infections in Adults and Adolescents with HIV. 2021 Feb 26. URL: https:/ /clinicalinfo.hiv.gov/sites/default/files/guidelines/documents/HIV_COVID_19_GL_2021.pdf [accessed 2021-08-19]

14. British HIV Association. 2021 Jan 11. URL: https://www.bhiva.org/ SARS-CoV-2-vaccine-advice-for-adults-living-with-HIV-plain-english-version-update [accessed 2021-08-19]

15. ASHM COVID-19 Taskforce. Statement from the ASHM COVID-19 Taskforce regarding the prioritization of COVID-19 vaccines for people living with HIV. Australasian Society for HIV, Viral Hepatitis and Sexual Health Medicine. 2021 Apr 14. URL: https://www.ashm.org.au/covid-19/clinical-care/statement-regarding-the-prioritisation-of-covid-19-vaccines/ [accessed 2021-08-19]

16. COVID-19 vaccines for moderately to severely immunocompromised people. Centers for Disease Control and Prevention. 2021 Oct 08. URL: https://www.cdc.gov/coronavirus/2019-ncov/vaccines/recommendations/immuno.html [accessed 2021-08-19]

17. Chapter of Infectious Disease Physicians. Consensus Statement on the Expansion of Eligibility for COVID-19 Vaccination for People Living With HIV in Singapore. Singapore: Chapter of Infectious Disease Physicians, College of Physicians, Academy of Medicine; 2021 Jun 28. URL: https://tinyurl.com/c4xj8e9k [accessed 2021-08-19]

18. National Health Commission of the People's Republic of China. Technical Guideline on COVID-19 Vaccination (1st Edition). URL: http://www.nhc.gov.cn/xcs/yqfkdt/202103/c2febfd04fc5498f916b1be080905771.shtml [accessed 2021-03-30]

19. Sallam M. COVID-19 vaccine hesitancy worldwide: A concise systematic review of vaccine acceptance rates. Vaccines (Basel) $2021 \mathrm{Feb} 16 ; 9(2): 160$ [FREE Full text] [doi: 10.3390/vaccines9020160] [Medline: $\underline{33669441]}$

20. COCONEL Group. A future vaccination campaign against COVID-19 at risk of vaccine hesitancy and politicisation. Lancet Infect Dis 2020 Jul;20(7):769-770 [FREE Full text] [doi: 10.1016/S1473-3099(20)30426-6] [Medline: 32445713]

21. Wang Z, She R, Chen X, Li L, Li L, Huang Z, et al. Parental acceptability of COVID-19 vaccination for children under the age of 18 years among Chinese doctors and nurses: A cross-sectional online survey. Hum Vaccin Immunother 2021 Oct 03;17(10):3322-3332. [doi: 10.1080/21645515.2021.1917232] [Medline: $\underline{34137670]}$

22. Vallée A, Fourn E, Majerholc C, Touche P, Zucman D. COVID-19 vaccine hesitancy among French people living with HIV. Vaccines (Basel) 2021 Mar 24;9(4):302 [FREE Full text] [doi: 10.3390/vaccines9040302] [Medline: 33804808]

23. Bogart L, Ojikutu B, Tyagi K, Klein D, Mutchler M, Dong L, et al. COVID-19 related medical mistrust, health impacts, and potential vaccine hesitancy among Black Americans living with HIV. J Acquir Immune Defic Syndr 2021 Feb 01;86(2):200-207 [FREE Full text] [doi: 10.1097/QAI.0000000000002570] [Medline: 33196555]

24. McLeroy KR, Bibeau D, Steckler A, Glanz K. An ecological perspective on health promotion programs. Health Educ Q 1988;15(4):351-377. [doi: 10.1177/109019818801500401] [Medline: 3068205]

25. Pan Y, Fang Y, Xin M, Dong W, Zhou L, Hou Q, et al. Self-reported compliance with personal preventive measures among Chinese factory workers at the beginning of work resumption following the COVID-19 outbreak: Cross-sectional survey study. J Med Internet Res 2020 Sep 29;22(9):e22457 [FREE Full text] [doi: 10.2196/22457] [Medline: 32924947]

26. Wang J, Jing R, Lai X, Zhang H, Lyu Y, Knoll MD, et al. Acceptance of COVID-19 vaccination during the COVID-19 pandemic in China. Vaccines (Basel) 2020 Aug 27;8(3):482 [FREE Full text] [doi: 10.3390/vaccines8030482] [Medline: 32867224]

27. Zhang KC, Fang Y, Cao H, Chen H, Hu T, Chen Y, et al. Behavioral intention to receive a COVID-19 vaccination among Chinese factory workers: Cross-sectional online survey. J Med Internet Res 2021 Mar 09;23(3):e24673 [FREE Full text] [doi: 10.2196/24673] [Medline: 33646966]

28. Wong MC, Wong EL, Huang J, Cheung AW, Law K, Chong MK, et al. Acceptance of the COVID-19 vaccine based on the health belief model: A population-based survey in Hong Kong. Vaccine 2021 Feb 12;39(7):1148-1156 [FREE Full text] [doi: 10.1016/j.vaccine.2020.12.083] [Medline: 33461834]

29. Wang K, Wong EL, Ho K, Cheung AW, Yau PS, Dong D, et al. Change of willingness to accept COVID-19 vaccine and reasons of vaccine hesitancy of working people at different waves of local epidemic in Hong Kong, China: Repeated cross-sectional surveys. Vaccines (Basel) 2021 Jan 18;9(1):62 [FREE Full text] [doi: 10.3390/vaccines9010062] [Medline: $\underline{33477725]}$

30. Yu Y, Lau JT, Lau MM, Wong MC, Chan PK. Understanding the prevalence and associated factors of behavioral intention of COVID-19 vaccination under specific scenarios combining effectiveness, safety, and cost in the Hong Kong Chinese general population. Int J Health Policy Manag 2021 Jan 18. [doi: 10.34172/ijhpm.2021.02] [Medline: $\underline{33619928]}$ 
31. Lau JT, Wang Z, Kim Y, Li J, Gu J, Mo PK, et al. Low sustainability, poor governance, and other challenges encountered by grassroots non-governmental organizations targeting HIV prevention for men who have sex with men in China - A nation-wide study. AIDS Care 2017 Dec;29(12):1480-1490. [doi: 10.1080/09540121.2017.1300630] [Medline: 28271717]

32. Michie S, Johnston M, Francis J, Hardeman W, Eccle M. From theory to intervention: Mapping theoretically derived behaviorual determinants to behaviour change techniques. Appl Psychol 2008;57:660-680. [doi:

10.1111/j.1464-0597.2008.00341.x]

33. Moreno MA, Whitehill JM. Influence of social media on alcohol use in adolescents and young adults. Alcohol Res 2014;36(1):91-100 [FREE Full text] [Medline: 26259003]

34. Poteat T, Wirtz AL, Radix A, Borquez A, Silva-Santisteban A, Deutsch MB, et al. HIV risk and preventive interventions in transgender women sex workers. Lancet 2015 Jan 17;385(9964):274-286 [FREE Full text] [doi:

10.1016/S0140-6736(14)60833-3] [Medline: 25059941]

35. COVID-19 Vaccines and HIV. Geneva, Switzerland: UNAIDS; 2021 Jun 01. URL: https://www.unaids.org/en/resources/ documents/2021/covid19-vaccines-and-hiv [accessed 2021-03-30]

36. Pan Y, Xin M, Zhang C, Dong W, Fang Y, Wu W, et al. Associations of mental health and personal preventive measure compliance with exposure to COVID-19 information during work resumption following the COVID-19 outbreak in China: Cross-sectional survey study. J Med Internet Res 2020 Oct 08;22(10):e22596 [FREE Full text] [doi: 10.2196/22596] [Medline: 32936776]

37. Zewude B, Habtegiorgis T. Willingness to take COVID-19 vaccine among people most at risk of exposure in Southern Ethiopia. Pragmat Obs Res 2021;12:37-47 [FREE Full text] [doi: 10.2147/POR.S313991] [Medline: $\underline{34079423]}$

\author{
Abbreviations \\ GOR: adjusted odds ratio \\ ART: antiretroviral therapy \\ CBO: community-based organization \\ CFI: comparative fit index \\ mRNA: messenger RNA \\ PLWHA: people living with HIV and AIDS \\ RMSEA: root mean square error of approximation \\ TLI: Tucker-Lewis index \\ WHO: World Health Organization
}

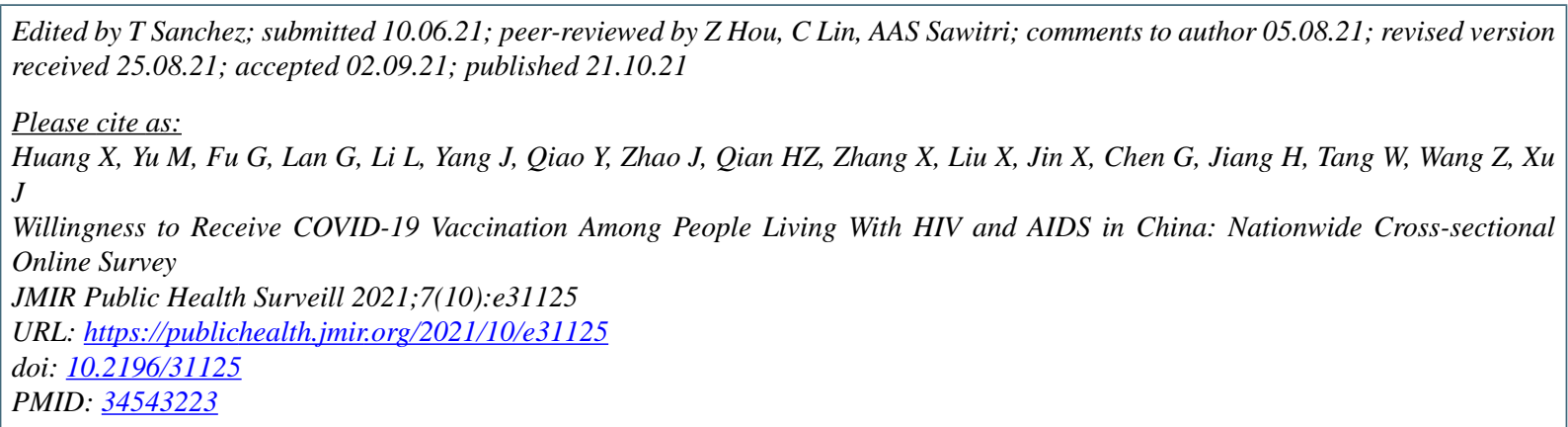

(CXiaojie Huang, Maohe Yu, Gengfeng Fu, Guanghua Lan, Linghua Li, Jianzhou Yang, Ying Qiao, Jin Zhao, Han-Zhu Qian, Xiangjun Zhang, Xinchao Liu, Xia Jin, Guohong Chen, Hui Jiang, Weiming Tang, Zixin Wang, Junjie Xu. Originally published in JMIR Public Health and Surveillance (https://publichealth.jmir.org), 21.10.2021. This is an open-access article distributed under the terms of the Creative Commons Attribution License (https://creativecommons.org/licenses/by/4.0/), which permits unrestricted use, distribution, and reproduction in any medium, provided the original work, first published in JMIR Public Health and Surveillance, is properly cited. The complete bibliographic information, a link to the original publication on https://publichealth.jmir.org, as well as this copyright and license information must be included. 